“C 2017 IEEE. Personal use of this material is permitted. Permission from IEEE must be obtained for all other uses, in any current or future media, including reprinting/republishing this material for advertising or promotional purposes, creating new collective works, for resale or redistribution to servers or lists, or reuse of any copyrighted component of this work in other works." 


\title{
A PI Controller with Current Feedforward to Improve the Steady-State Error Performance for a Current Controlled Direct Matrix Converter
}

\author{
Jianwei Zhang ${ }^{1}, \mathrm{Li} \mathrm{Li}^{1}$, David Dorrell ${ }^{2}$, and Youguang Guo ${ }^{1}$ \\ ${ }^{1}$ Faculty of Engineering and IT, University of Technology Sydney, Sydney, Australia \\ ${ }^{2}$ University of KwaZulu-Natal, Howard College Campus, Durban, South Africa \\ Email: Jianwei.Zhang@uts.edu.au, Li.Li@uts.edu.au, dorrelld@ukzn.ac.za and Youguang.Guo-1@uts.edu.au
}

\begin{abstract}
Traditional PI controllers can have poor regulation performance due to steady state errors when tracking sinusoidal signals. Hence synchronous PI controllers are often used, although this controller requires reference frame transformations. In this paper, a modified PI controller, which uses current feedforward, is developed to control the output currents of a matrix converter. The controller is implemented in the natural frame $(a b c)$ together with space vector modulation. The output current is then controlled. This controller does not require any frame transformation and it demonstrates improved steady-state tracking performance. The total harmonic distortion is improved at the same time. A constant switching frequency is maintained because of the application of the modulation stage. Simulation results verify the feasibility and effectiveness of the proposed controller.
\end{abstract}

Index Terms-Matrix Converter, Stationary PI Controller, Current Forward Control, Steady-State Errors

\section{INTRODUCTION}

PI controllers are simple, easy to implement and have been widely employed in power converters and other industrial applications [1]. PI controllers, as used in a power electronic converter, are generally classified into three categories: synchronous reference frame $(d q$ system), stationary reference frame ( $\alpha \beta$ system), and natural frame ( $a b c$ system) based. Both $\alpha \beta$ and $d q$ based control methods require multiple frame transformations (Clark and/or Park) leading to the increased computation burden. Due to significant amplitude and phase tracking errors, stationary frame PI controllers are considered as unsatisfactory controllers. The reason for the steady-state errors in a stationary PI controller has been attributed to the fact that the stationary controller only offers a limited gain at nonzero frequencies [2], [3]. In contrast, the synchronous PI controller has been widely applied as it can achieve zero steady-state error because of the infinite gain at the DC signal provided by the integral term.

However, the synchronous frame controller is more sophisticated than the stationary frame controller due to the complex transformations required $(a b c \leftrightarrow d q)$ to convert the controlled signals to DC quantities. They are also error prone to the noise in the synchronous reference signal detection which is usually captured using a phase locked loop (PLL). This introduces extra errors and becomes even worse for a single-phase system.

Some modified PI controllers have been proposed in the literature. Some of these involve a feedforward controller. Feedforward control is simple in concept,

This work is supported in part by the China Scholarship Council (File No. 201406300161) robust and has good dynamic performance [4]. It is especially effective in handling a disturbance that can be measured. The stationary PI controller with a grid voltage feedforward path (shown in Fig. 1) was proposed in [5] for a grid-tied converter to improve the transient and disturbance rejection performance. However this scheme suffers from voltage background harmonics and stability problems [6].

A combined feedforward-feedback controller, as shown in Fig. 2, was proposed to improve the overall performance of the whole control system. A combined feedforward-feedback controller has been used in other fields such as chemistry and mechanical systems [7]-[11]. However, it has drawn little attention in terms of the power electronic converter.

This paper investigates the combined feedforwardfeedback PI controller for a three-phase direct matrix converter (shown in Fig. 3). The matrix converter is a promising converter thanks to various benefits it provides including bidirectional power flow, compact volume, sinusoidal waveform, direct conversion, and controllable input power factor [12]. Space vector modulation (SVM) is an effective and common control technique for the matrix converter. However, it is ineffective when the load is unknown as this method requires the output current in the modulation. A synchronous PI controller using SVM was proposed in [12] and [13] for a matrix converter to control the power flow in a transmission system. However, the issues associated with synchronous PI controllers persisted.

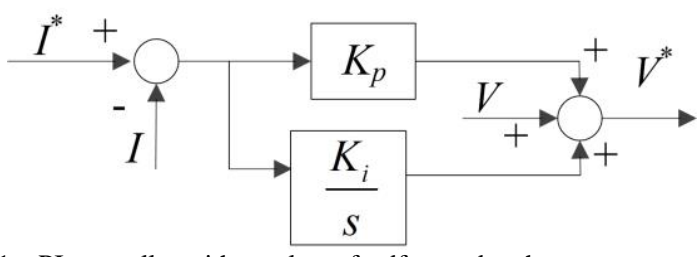

Fig. 1. PI controller with a voltage feedforward path.

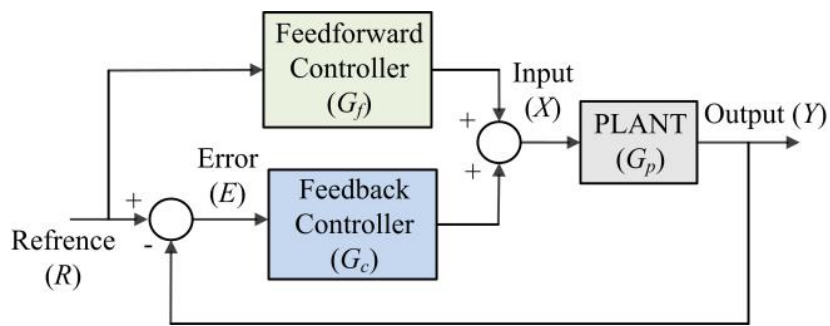

Fig. 2. Combined feedforward and feedback controller diagram. 


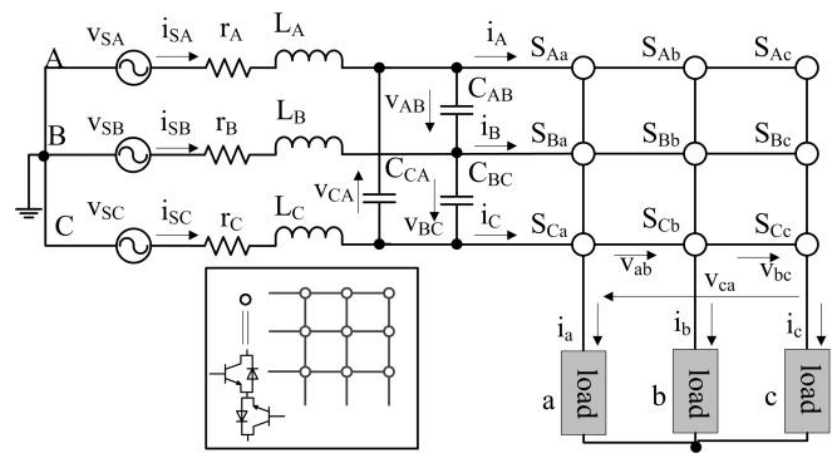

Fig. 3. Three-phase direct matrix converter system.

The focus of this paper is to improve the steady-state error performance of the PI controller when controlling sinusoidal signals in the natural frame. The current reference is fed forward to the controller, which results in a combined feedforward-feedback controller. The controller is implemented in the natural frame, so the frame transformations are not needed. The SVM is employed as a modulator with which the constant frequency is maintained. Although the matrix converter is investigated as an example, the controller can be easily extended to other converters and applications.

\section{PI CONTROLLER WITH CURRENT FEEDFORWARD}

The combined feedforward-feedback controller is shown in Fig. 2, where the current reference is fed forward as a control effort. This will benefit the improvement of the steady-state error performance. The transfer function $E(s) / R(s)$ is given by

$$
\frac{E(s)}{R(s)}=\frac{1-G_{f}(s) G_{p}(s)}{1+G_{c}(s) G_{p}(s)}
$$

where $G_{c}$ is the PI controller; $G_{f}$ is the feedforward controller (proportional controller); and $G_{p}$ is the plant system of the inductive load. These are given by

$$
G_{c}(s)=\frac{K_{p} s+K_{i}}{s}, \quad G_{f}(s)=K, \quad G_{p}(s)=\frac{1}{R+L s}
$$

This is then a two-degrees-of-freedom control system in which the closed-loop characteristics and the feedback characteristics can be regulated independently to improve the overall response performance of the whole control system [14]. By rearranging (1), the error in the frequency domain is obtained as

$$
E(s)=\frac{1-G_{f}(s) G_{p}(s)}{1+G_{c}(s) G_{p}(s)} \cdot R(s)
$$

The reference $R$ in the natural frame is usually a sinusoidal function $R(t)=I_{r} \sin \left(\omega_{c} t\right)$ and its frequency domain expression (Laplace transform) is

$$
R(s)=I_{r} \frac{\omega_{c}}{s^{2}+\omega_{c}^{2}}
$$

where $I_{r}$ is the reference amplitude and $\omega_{c}=2 \pi f$ is the reference angular frequency. By substituting (3) into (2),

$$
E(s)=\frac{L s^{2}+(R-K) s}{L s^{2}+\left(K_{p}+R\right) s+K_{i}} \cdot I_{r} \frac{\omega_{c}}{s^{2}+\omega_{c}^{2}}
$$

is obtained. In order to derive the amplitude and phase responses of the error $E(\mathrm{~s}), s$ is substituted by $j \omega$. Therefore, the amplitude and phase angles are obtained from:

$$
\begin{gathered}
|E(s)|=\sqrt{\frac{\omega^{2} L^{2}+(R-K)^{2}}{\left(K_{i}-\omega^{2} L\right)^{2}+\left(K_{p}+R\right)^{2} \omega^{2}}} \cdot \frac{I_{r} \omega \omega_{c}}{-\omega^{2}+\omega_{c}^{2}} \\
\angle E(s)=\tan ^{-1} \frac{(R-K)}{-L \omega}-\tan ^{-1} \frac{\left(K_{p}+R\right) \omega}{K_{i}-L \omega^{2}}
\end{gathered}
$$

According to (5) and (6), the amplitude and phase angle of the error will have a minimum value when $K=R$ while other parameters are fixed. The introduction of the feedforward controller $K$ offers extra flexibility to tune the steady-state error performance. The amplitude and phase responses for different values of $K$ are depicted in Fig. 4. Here, the parameters used are: $K_{p}=10, K_{i}=1, R=$ $20 \Omega, L=15 \mathrm{mH}, \omega_{c}=120 \pi \mathrm{rad} / \mathrm{s}$. As can be seen from the figure, the amplitude response for $K=R$ is particularly distinct from others and it has the minimum level of the amplitude response for the whole frequency domain. According to this, a correct selection of $K$ can help reduce the steady-state error. Therefore, the proposed PI controller with current feedforward for controlling the matrix converter output currents is shown in Fig. 5.

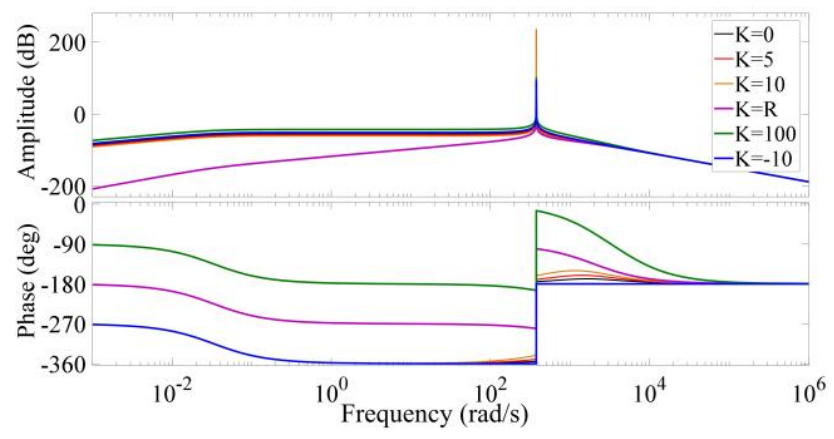

Fig. 4. Amplitude and phase responses of $E(s)$ for different values of $K$.

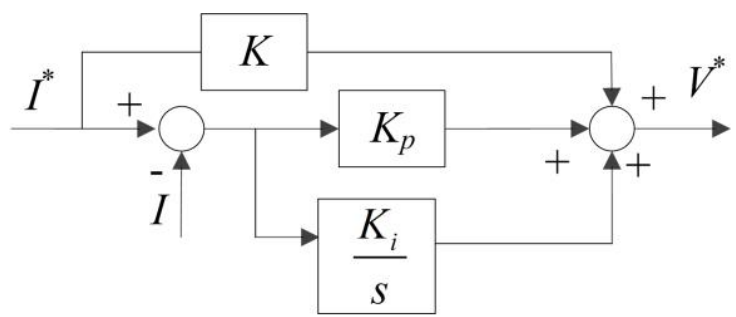

Fig. 5. Proposed PI current controller with current reference feedforward for matrix converter. 
This controller is implemented in the natural $a b c$ frame (stationary) which does not require any frame transformations. Therefore, the complexity and computation burden is alleviated. The controller generates the voltage references which will be utilized in the SVM to control the matrix converter. The SVM is described in the next section.

\section{INDIRECT SVM FOR THE MATRIX CONVERTER}

A modulation stage is required in the proposed control strategy to control the matrix converter. SVM is a developed modulation technique and it is adopted here. There are two ways to implement the SVM for the controller: direct and indirect methods [3].

In the direct method, the PI controller forms a current loop and generates output voltage references based on the output current errors (reference - actual). The matrix converter input current references are specified according to the system requirements. Then output voltage and input current references are directly used in the SVM to generate gating pulses for the semiconductor switches in the matrix converter [13].

In the indirect method, SVM is divided into virtual inversion and rectification modulation stages. In the virtual inversion modulation stage, the PI controller and SVM (for the inverter only) are used to generate gating pulses for the semiconductors switches in the virtual inverter. The SVM (for the rectifier only) is used in the virtual rectification modulation stage to generate gating pulses for the semiconductor switches in the virtual rectifier. Then the two virtual modulation stages are combined to control the matrix converter [12]. In this work, the indirect method is employed.

In indirect SVM, the virtual DC link, shown in Fig. 6, is used to connect the virtual voltage source rectifier (VSR) and the virtual voltage source inverter (VSI). It is worth noting that the virtual DC link does not really exist in the matrix converter. It is only used for explaining the modulation technique. By applying SVM to each stage, and then combining them, the overall indirect SVM for the matrix converter can be derived.

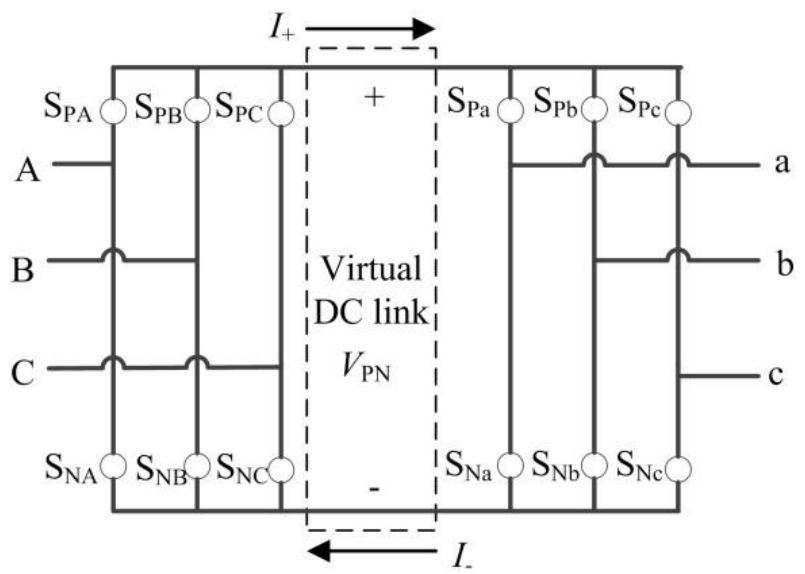

Fig. 6. Indirect SVM illustration with virtual DC link.

\section{A. SVM for the Virtual Rectifier}

In the VSR, the control objectives are the input currents. In SVM, the currents in the three-phase system can be transformed into space vectors using:

$$
x_{S}=\frac{2}{3}\left(x_{1}+\alpha x_{2}+\alpha^{2} x_{3}\right)
$$

where $x_{1,2,3}$ are the variables in the three-phase system; $\alpha$ $=e^{j(2 \pi / 3)}$ and $\alpha^{2}=e^{j(4 \pi / 3)} ; x_{s}$ is the corresponding space vector after the transformation. From Fig. 6, the input currents can be controlled by controlling the switch matrix:

$$
\begin{aligned}
& {\left[\begin{array}{l}
I_{A} \\
I_{B} \\
I_{C}
\end{array}\right]=\left[\begin{array}{ll}
S_{A P} & S_{A N} \\
S_{B P} & S_{B N} \\
S_{C P} & S_{C N}
\end{array}\right]\left[\begin{array}{c}
I_{+} \\
I_{-}
\end{array}\right]} \\
& {\left[\begin{array}{l}
V_{+} \\
V_{-}
\end{array}\right]=\left[\begin{array}{lll}
S_{A P} & S_{B P} & S_{C P} \\
S_{A N} & S_{B N} & S_{C N}
\end{array}\right]\left[\begin{array}{c}
V_{A} \\
V_{B} \\
V_{C}
\end{array}\right]}
\end{aligned}
$$

\begin{tabular}{|c|c|c|c|c|}
\hline \multicolumn{2}{|c|}{ No. on-state swithches } & rectifier current vectors & DC voltages & group \\
\hline R1 & $\mathrm{S}_{\mathrm{PA}}, \mathrm{S}_{\mathrm{NC}}$ 해애 & $I_{R 1}=\frac{2 \sqrt{3}}{3} I_{+} e^{j \frac{\pi}{6}}$ & $\begin{array}{l}V_{+}=V_{\mathrm{A}} \\
V_{-}=V_{\mathrm{C}}\end{array}$ & \multirow{6}{*}{$\begin{array}{l}\text { non } \\
\text { zero }\end{array}$} \\
\hline R2 & $\mathrm{S}_{\mathrm{PB}}, \mathrm{S}_{\mathrm{NC}}$ & $I_{R 2}=\frac{2 \sqrt{3}}{3} I_{+} e^{j \frac{\pi}{2}}$ & $\begin{array}{l}V_{+}=V_{\mathrm{B}} \\
V_{-}=V_{\mathrm{C}}\end{array}$ & \\
\hline R3 & $\mathrm{S}_{\mathrm{PB}}, \mathrm{S}_{\mathrm{NA}}$ & $I_{R 3}=\frac{2 \sqrt{3}}{3} I_{+} e^{j \frac{5 \pi}{6}}$ & $\begin{array}{l}V_{+}=V_{\mathrm{B}} \\
V_{-}=V_{\mathrm{A}}\end{array}$ & \\
\hline R4 & $\mathrm{S}_{\mathrm{PC}}, \mathrm{S}_{\mathrm{NA}}$ & $I_{R 4}=\frac{2 \sqrt{3}}{3} I_{+} e^{j \frac{7 \pi}{6}}$ & $\begin{array}{l}V_{+}=V_{\mathrm{C}} \\
V_{-}=V_{\mathrm{A}}\end{array}$ & \\
\hline R5 & $\mathrm{S}_{\mathrm{PC}}, \mathrm{S}_{\mathrm{NB}} \equiv$ & $I_{R 5}=\frac{2 \sqrt{3}}{3} I_{+} e^{j \frac{3 \pi}{2}}$ & $\begin{array}{l}V_{+}=V_{\mathrm{C}} \\
V_{-}=V_{\mathrm{B}}\end{array}$ & \\
\hline R6 & $\mathrm{S}_{\mathrm{PA}}, \mathrm{S}_{\mathrm{NB}}$ & $I_{R 6}=\frac{2 \sqrt{3}}{3} I_{+} e^{j \frac{11 \pi}{6}}$ & $\begin{array}{l}V_{+}=V_{\mathrm{A}} \\
V_{-}=V_{\mathrm{B}}\end{array}$ & \\
\hline R7 & $\mathrm{S}_{\mathrm{PA}}, \mathrm{S}_{\mathrm{NA}}$ और्षक & $I_{R 7}=0$ & $\begin{array}{l}V_{+}=V_{\mathrm{A}} \\
V_{-}=V_{\mathrm{A}}\end{array}$ & \multirow{3}{*}{ zero } \\
\hline R8 & $\mathrm{S}_{\mathrm{PB}}, \mathrm{S}_{\mathrm{NB}}$ 丮象 & $I_{R 8}=0$ & $\begin{array}{l}V_{+}=V_{\mathrm{B}} \\
V_{-}=V_{\mathrm{B}}\end{array}$ & \\
\hline R9 & $\mathrm{S}_{\mathrm{PC}}, \mathrm{S}_{\mathrm{NC}}$ 我 & $I_{R 9}=0$ & $\begin{array}{l}V_{+}=V_{\mathrm{C}} \\
V_{-}=V_{\mathrm{C}}\end{array}$ & \\
\hline
\end{tabular}

TABLE I

POSSIBLE SWITCH STATES FOR THE VSR

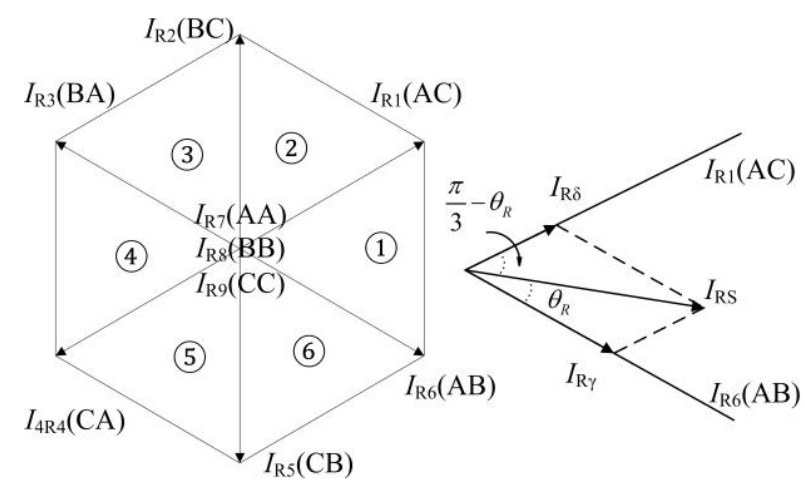

Fig. 7. (a) VSR current space vectors hexagon, (b) space vector synthesis. 
In (8) and (9), each switch element can have two different values ( 1 for on state and 0 for off state). In order to exclude the switch states that short circuit the input voltage sources, the constraints of $S_{P A}+S_{P B}+S_{P C}=1$ and $S_{N A}+S_{N B}+S_{N C}=1$ have to be applied.

There are nine possible switch combinations which correspond to nine current vectors generated by the DC link currents. These include six non-zero vectors and three zero vectors (tabulated in Table I) and they form a vector hexagon (shown in Fig. 7. (a)). The desired current vectors are synthesized with a combination of these vectors depending on its sector location. In each sector, two adjacent non-zero vectors and one zero vector are used to synthesize the desired vector as shown in Fig. 7. (b). For example, if the desired current vector is located in sector (1), then $I_{R 1}, I_{R 6}$ and a zero vector will be selected in the corresponding switching cycle. The prescribed working time for each vector is calculated using

$$
\begin{gathered}
t_{R \gamma}=\frac{2}{\sqrt{3}} \frac{I_{i}}{I_{+}} \sin \left(\frac{\pi}{3}-\theta_{R}\right) T_{s} \quad t_{R \delta}=\frac{2}{\sqrt{3}} \frac{I_{i}}{I_{+}} \sin \left(\theta_{R}\right) T_{s} \\
t_{R 0}=T_{s}-\left(t_{R \gamma}+t_{R \delta}\right), \quad m_{i}=\frac{2}{\sqrt{3}} \frac{I_{i}}{I_{+}}
\end{gathered}
$$

where $t_{R \delta}$ and $t_{R \gamma}$ are the times for the application of nonzero vectors; $t_{R 0}$ is the time for the application of zero vectors; $T_{s}$ is the switching period; and $m_{i}$ is the VSR modulation index.

\section{B. SVM for the Virtual Inverter}

In VSI, the control objective are the output voltages. As shown in Fig. 6, the output voltages can be regulated by controlling the switch matrix in:

$$
\begin{gathered}
{\left[\begin{array}{c}
V_{a} \\
V_{b} \\
V_{c}
\end{array}\right]=\left[\begin{array}{ll}
S_{P a} & S_{N a} \\
S_{P b} & S_{N b} \\
S_{P c} & S_{N c}
\end{array}\right]\left[\begin{array}{c}
V_{+} \\
V_{-}
\end{array}\right]} \\
{\left[\begin{array}{l}
I_{+} \\
I_{-}
\end{array}\right]=\left[\begin{array}{lll}
S_{P a} & S_{P b} & S_{P c} \\
S_{N a} & S_{N b} & S_{N c}
\end{array}\right]\left[\begin{array}{c}
I_{a} \\
I_{b} \\
I_{c}
\end{array}\right]}
\end{gathered}
$$

Here the constraints of $S_{P a}+S_{N a}=1, S_{P b}+S_{N b}=1$ and $S_{P c}+S_{N c}=1$, are applied to avoid the switch states that open circuit the inductive loads.

Therefore, there are eight possible switch combinations, thus eight voltage vectors, and they are tabulated in Table II and shown in Fig. 8. (a). Like the description above for the VSR, the working time for the vectors is calculated using

$$
\begin{gathered}
t_{I \alpha}=\frac{2}{\sqrt{3}} \frac{V_{o}}{V_{P N}} \sin \left(\frac{\pi}{3}-\theta_{I}\right) T_{s} \\
t_{I \beta}=\frac{2}{\sqrt{3}} \frac{V_{o}}{V_{P N}} \sin \left(\theta_{I}\right) T_{s} \\
t_{I 0}=T_{s}-\left(t_{I \alpha}+t_{I \beta}\right), \quad m_{v}=\frac{2}{\sqrt{3}} \frac{V_{o}}{V_{P N}}
\end{gathered}
$$

where $t_{I \alpha}$ and $t_{I \beta}$ are the times for the applications of nonzero vectors; $t_{I 0}$ is the time for the application of zero vectors and $m_{i v}$ is the VSI modulation index. The selection of the zero vectors in both SVMs should benefit the reduction of switching actions, thus switching losses.

\section{Overall Modulation}

Combining the VSR and VSI stages, the overall SVM for the whole matrix converter can be obtained. Based on

\begin{tabular}{|c|c|c|c|c|}
\hline No. & on-state swithches & inverter voltage vectors & DC currents & group \\
\hline I1 & 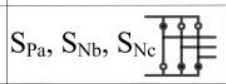 & $V_{I 1}=\frac{2}{3} V_{P N} e^{j 0}$ & $\begin{array}{l}I_{+}=I_{\mathrm{a}} \\
I_{-}=I_{\mathrm{b}}+I_{\mathrm{c}}\end{array}$ & \multirow{6}{*}{$\begin{array}{l}\text { non } \\
\text { zero }\end{array}$} \\
\hline 12 & 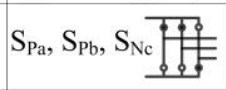 & $V_{I 2}=\frac{2}{3} V_{P N} e^{j \frac{\pi}{3}}$ & $\begin{array}{l}I_{+}=I_{\mathrm{a}}+I_{\mathrm{b}} \\
I_{-}=I_{\mathrm{c}}\end{array}$ & \\
\hline I3 & 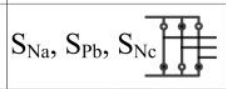 & $V_{I 3}=\frac{2}{3} V_{P N} e^{j \frac{2 \pi}{3}}$ & $\begin{array}{l}I_{+}=I_{\mathrm{b}} \\
I_{-}=I_{\mathrm{a}}+I_{\mathrm{c}}\end{array}$ & \\
\hline I4 & 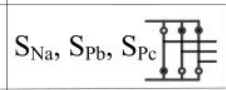 & $V_{I 4}=\frac{2}{3} V_{P N} e^{j \pi}$ & $\begin{array}{l}I_{+}=I_{\mathrm{b}}+I_{\mathrm{c}} \\
I_{-}=I_{\mathrm{a}}\end{array}$ & \\
\hline I5 & $\mathrm{S}_{\mathrm{Na}}, \mathrm{S}_{\mathrm{Nb}}, \mathrm{S}_{\mathrm{P}}$ & $V_{15}=\frac{2}{3} V_{P N} e^{j \frac{4 \pi}{3}}$ & $\begin{array}{l}I_{+}=I_{\mathrm{c}} \\
I_{-}=I_{\mathrm{a}}+I_{\mathrm{b}}\end{array}$ & \\
\hline I6 & 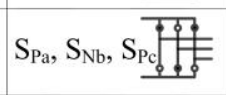 & $V_{I 6}=\frac{2}{3} V_{P N} e^{j \frac{5 \pi}{3}}$ & $\begin{array}{l}I_{+}=I_{\mathrm{a}}+I_{\mathrm{c}} \\
I_{=}=I_{\mathrm{b}}\end{array}$ & \\
\hline 17 & 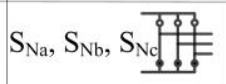 & $V_{17}=0$ & $\begin{array}{l}I_{+}=0 \\
I_{-}=0\end{array}$ & \multirow{2}{*}{ zero } \\
\hline I8 & 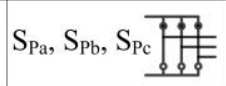 & $V_{18}=0$ & $\begin{array}{l}I_{+}=0 \\
I_{-}=0\end{array}$ & \\
\hline
\end{tabular}
(8), (9), (14) and (15) the switch matrix $S$ can be derived as:

$$
\begin{aligned}
& S=\left[\begin{array}{ll}
S_{P A} & S_{N A} \\
S_{P B} & S_{N B} \\
S_{P B} & S_{N C}
\end{array}\right]\left[\begin{array}{lll}
S_{P a} & S_{P b} & S_{P c} \\
S_{N a} & S_{N b} & S_{N c}
\end{array}\right] \\
& =\left[\begin{array}{lll}
S_{P A} S_{P a}+S_{N A} S_{n a} & S_{P A} S_{P b}+S_{N A} S_{N b} & S_{P A} S_{P c}+S_{N A} S_{N c} \\
S_{P B} S_{P a}+S_{N B} S_{n a} & S_{B p} S_{P b}+S_{N B} S_{N b} & S_{B p} S_{P c}+S_{N B} S_{N c} \\
S_{P C} S_{P a}+S_{N C} S_{n a} & S_{C p} S_{P b}+S_{N C} S_{N b} & S_{C p} S_{P c}+S_{N C} S_{N c}
\end{array}\right] \\
& =\left[\begin{array}{lll}
S_{A a} & S_{B a} & S_{C a} \\
S_{A b} & S_{B b} & S_{C b} \\
S_{A c} & S_{B c} & S_{C c}
\end{array}\right]
\end{aligned}
$$

TABLE II

POSSIBLE SWITCH STATES OF THE VSI

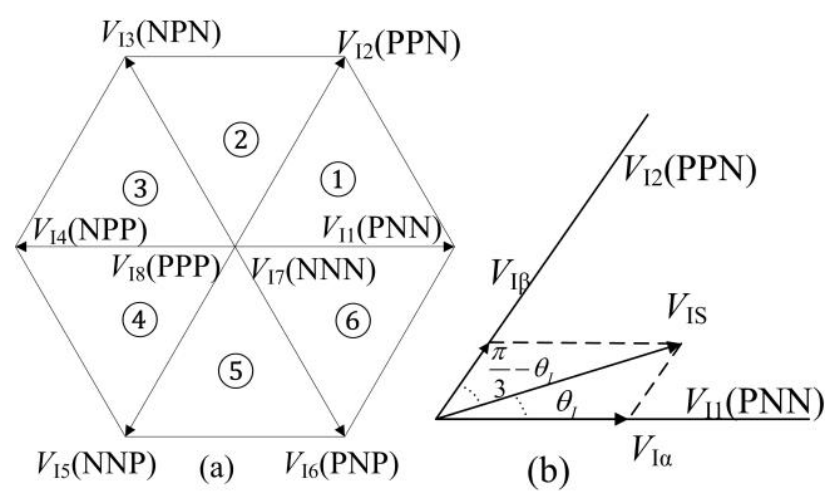

Fig. 8. (a) VSI voltage space vectors hexagon, (b) space vector synthesis. 


$$
\left[\begin{array}{l}
V_{a} \\
V_{b} \\
V_{c}
\end{array}\right]=S\left[\begin{array}{l}
V_{A} \\
V_{B} \\
V_{C}
\end{array}\right], \quad\left[\begin{array}{l}
I_{A} \\
I_{B} \\
I_{C}
\end{array}\right]=S^{T}\left[\begin{array}{l}
I_{a} \\
I_{b} \\
I_{c}
\end{array}\right]
$$

Every element in the 3 by 3 matrix in (20) corresponds to one switch in the matrix converter. For example, the first element $S_{A a}$ indicates the connection of the input phase $A$ to the output phase $a$. This is equivalent to the connection of $A$ to $a$ through $\left(S_{P A}\right.$ and $\left.S_{P a}\right)$ or through $\left(S_{N A}\right.$ and $S_{N a}$ ), as shown in Fig. 6. Applying the same rule, the switch states of the matrix converter can be determined. Hence the corresponding times of $t_{\gamma \alpha}, t_{\delta \alpha}, t_{\gamma \delta}, t_{\mathrm{I} \beta}$ and $t_{0}$ in the matrix converter are given by

$$
\begin{gathered}
t_{\gamma \alpha}=t_{R \gamma} \cdot t_{I \alpha}=m \sin \left(\frac{\pi}{3}-\theta_{R}\right) \sin \left(\frac{\pi}{3}-\theta_{I}\right) \\
t_{\delta \alpha}=t_{R \delta} \cdot t_{I \alpha}=m \sin \left(\theta_{R}\right) \sin \left(\frac{\pi}{3}-\theta_{I}\right) \\
t_{\gamma \beta}=t_{R \gamma} \cdot t_{I \beta}=m \sin \left(\frac{\pi}{3}-\theta_{R}\right) \sin \left(\theta_{I}\right) \\
t_{\delta \beta}=t_{R \delta} \cdot t_{I \beta}=m \sin \left(\theta_{R}\right) \sin \left(\theta_{I}\right) \\
t_{0}=T_{s}-\left(t_{\gamma \alpha}+t_{\delta \alpha}+t_{\gamma \beta}+t_{\delta \beta}\right)
\end{gathered}
$$

where $0 \leq \theta_{\mathrm{R}}\left(\theta_{\mathrm{I}}\right) \leq \pi / 3$ is the angle between the desired space vector $I_{\mathrm{RS}}\left(V_{I S}\right)$ and the right-hand adjacent vector $I_{\mathrm{R} \gamma}\left(V_{\mathrm{I} \alpha}\right) ; m=m_{i} \times m_{v}$ is the modulation index. Therefore, the input currents and output voltages of the matrix converter can be controlled.

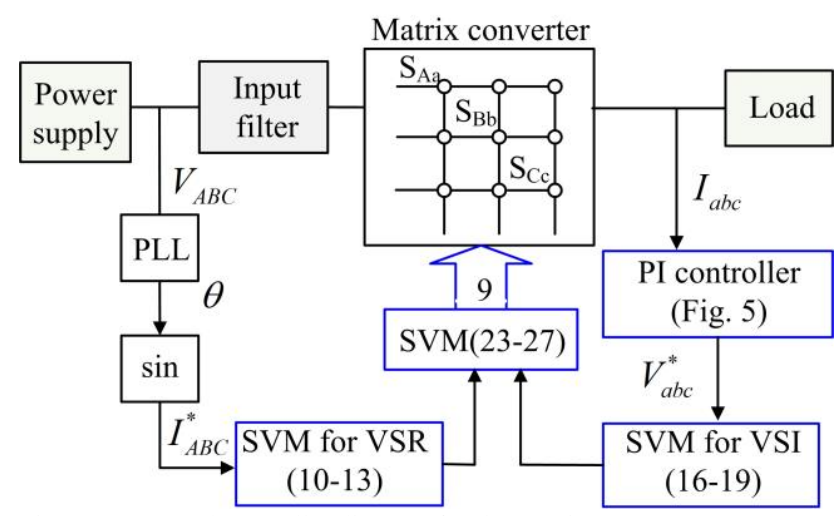

Fig. 9. Proposed controller diagram for the matrix converter.

TABLE III

SIMULATION SYSTEM PARAMETERS

\begin{tabular}{|c|c|c|c|c|c|c|}
\hline $\boldsymbol{V}_{\boldsymbol{i}}[\mathbf{V}]$ & $\boldsymbol{f}_{\boldsymbol{i}}[\mathbf{H z}]$ & $\boldsymbol{L}_{\boldsymbol{A}}[\mathbf{m H}]$ & $\boldsymbol{r}_{\boldsymbol{A}}[\mathbf{\Omega}]$ & $\boldsymbol{C}_{\boldsymbol{A} \boldsymbol{B}}[\boldsymbol{\mu \mathbf { F }}]$ & $\mathbf{L}[\mathbf{m H}]$ & $\boldsymbol{R}[\mathbf{\Omega}]$ \\
\hline 100 & 50 & 4.8 & 0.5 & 6 & 15 & 20 \\
\hline
\end{tabular}

\section{Simulation Results}

According to above analyses of the PI controller and SVM modulation, the proposed PI controller with current feedforward for the SVM modulated matrix converter can be designed as shown in Fig. 9. Simulation results are presented in this section. Simulation parameters are tabulated in Table III. The parameters used in the PI controller are $K_{p}=300$ and $K_{i}=10$.

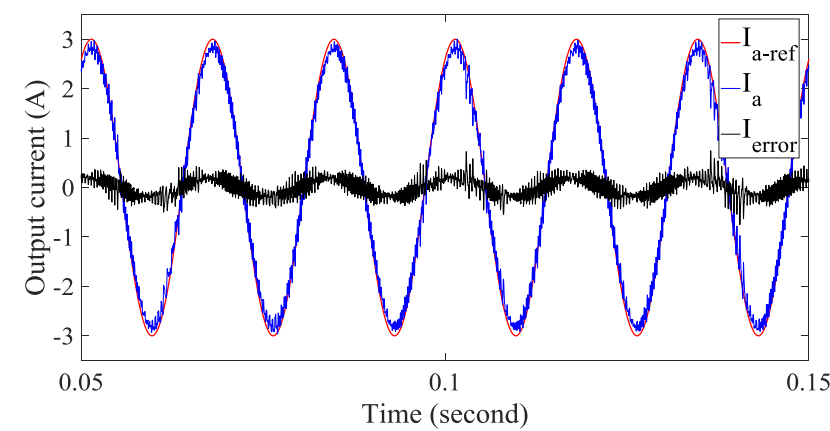

(a)

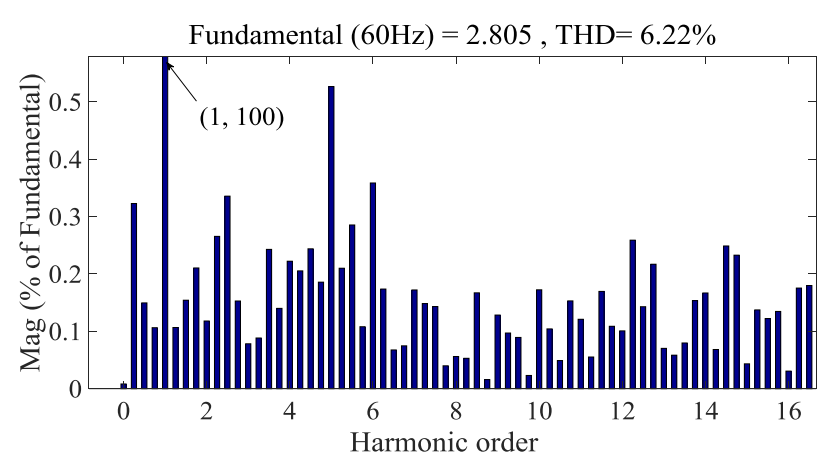

(b)

Fig. 10. Simulation results of the PI controller without current feedforward: (a) steady-state output currents and errors and (b) THD analysis of the currents.

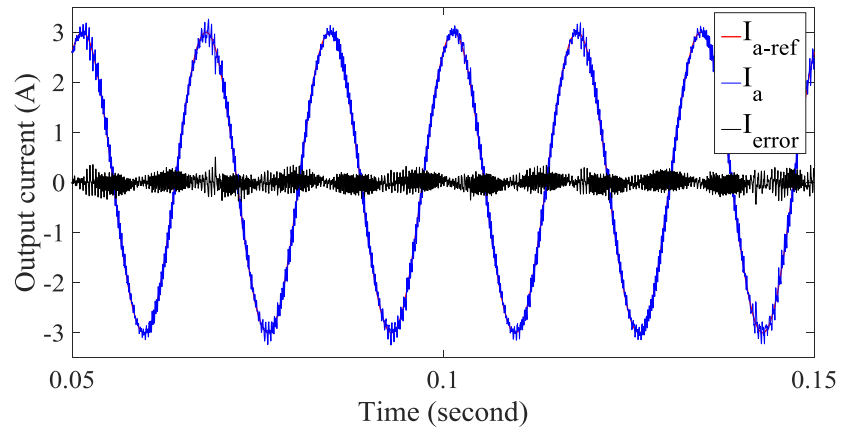

(a)

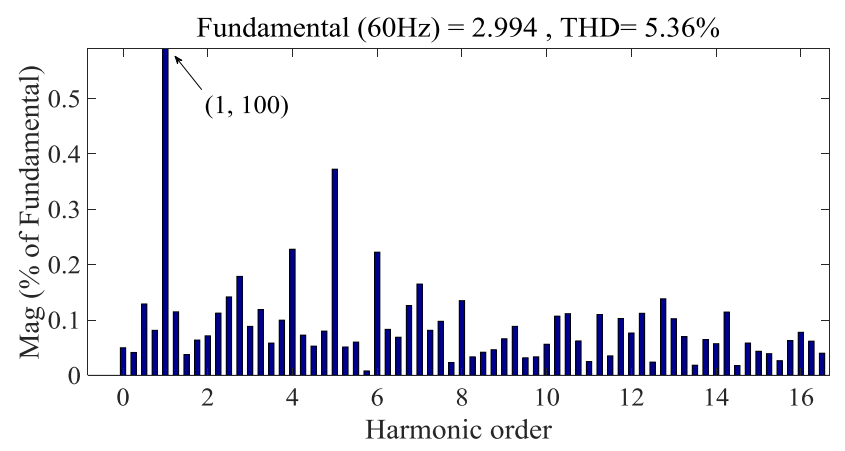

(b)

Fig. 11. Simulation results of the PI controller with current feedforward: (a) steady-state output currents and errors and (b) THD analysis of the currents. 


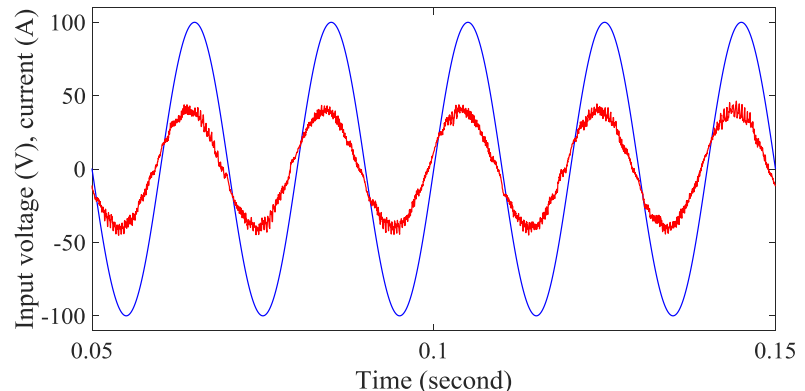

Fig. 12. Matrix converter input phase current and voltage.

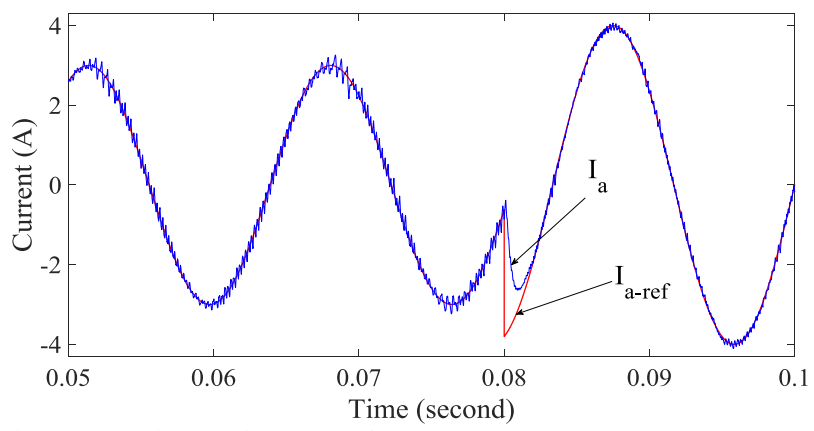

Fig. 13. Transient performance of the proposed controller.

Comparative simulation results are shown in Fig. 10 and 11. Fig. 10 shows the steady-state results for the normal PI controller without current feedforward. The obvious steady-state error appears in the waveform. The reference peak current is $3 \mathrm{~A}$, while the regulated current peak only reaches 2.8 A with a total harmonic distortion (THD) of $6.22 \%$.

In contrast, the steady-state error performance is significantly improved with the current feedforward ( $K=$ $R=20$ while $K_{p}$ and $K_{i}$ are kept same as before), as shown in Fig. 11. The steady-state current amplitude reaches $2.99 \mathrm{~A}$ and the THD is reduced to $5.36 \%$ at the same time. By comparing Fig. 10(b) and Fig. 11(b), it can be seen that both low-order and high-order harmonics are appreciably reduced.

The matrix converter input voltage and current of phase $A$ are shown in Fig. 12. As seen in this figure, the matrix converter current is almost in phase with the input voltage. A small phase shift is caused by the input filters, due to the fact that the input current is controlled in the open loop approach. The transient performance of the proposed controller is shown in Fig. 13. This result shows fast-dynamic response of the proposed controller. It is worth mentioning that the modulation index of the matrix converter influences the controller performance. This can be observed in Fig. 13 where different current amplitudes correspond to different modulation indexes.

\section{CONCLUSIONS}

A modified PI controller with current feedforward is proposed in this paper for a matrix converter to improve the steady-state error performance of the PI controller. The introduction of the feedforward control provides an extra freedom to improve the steady-state error performance. Analytical results show that the optimal performance can be achieved when $K=R$. The SVM modulation stage is employed to control the matrix converter. The proposed controller is simple and it does not require reference frame transformations. Constant switching frequency is achieved because of the modulation stage. Simulation results and comparative study verify the effectiveness of the proposed controller. The proposed combined feedforward-feedback control technique can be readily extended to other power electronic converters and other PI control applications.

\section{REFERENCES}

[1] J. Rocabert, A. Luna, F. Blaabjerg, and P. Rodriguez, "Control of power converters in AC microgrids," IEEE Trans. Ind. Electron., vol. 27, no. 11, pp. 4734-4749, 2012.

[2] Y. Han, P. Shen, and J. M. Guerrero, "Stationary frame current control evaluations for three-phase grid-connected inverters with PVR-based active damped LCL filters," $J$. Power Electron., vol. 16, no. 1, pp. 297-309, 2016.

[3] J. Zhang, L. Li, D. Dorrell and Y. Guo, "SVM based Proportional Resonant Current Controller with Selective Harmonics Compensation for Matrix Converter Systems," 20th International Conference on Electrical Machines and Systems (ICEMS), Sydney, 2017, Unpublished.

[4] R. Redl, "Feedforward control of switching regulators," in Analog Circuit Design, Springer Netherlands, pp. 321-338., 2012.

[5] G. Shen, D. Xu, L. Cao, and X. Zhu, "An improved control strategy for grid-connected voltage source inverters with an LCL filter," IEEE Trans. Power Electron., vol. 23, no. 4, pp. 1899-1906, 2008.

[6] R. Teodorescu, F. Blaabjerg, M. Liserre, and P. C. Loh, "Proportional-resonant controllers and filters for gridconnected voltage-source converters," IEE Proc. Electric Power Applicat., vol. 153, no. 5, pp. 750-762, 2006

[7] H. Zhang, and J. Wang, "Combined feedback-feedforward tracking control for networked control systems with probabilistic delays," J. the Franklin Institute, vol. 351, no. 6, pp. 3477-3489, 2014.

[8] A. Koerber, and R. King, "Combined feedbackfeedforward control of wind turbines using stateconstrained model predictive control," IEEE Trans. Control Syst. Tech., vol. 21, no. 4, pp.1117-1128, 2013.

[9] L. Y. Pao, J. A. Butterworth, and D. Y. Abramovitch, "Combined feedforward/feedback control of atomic force microscopes," In American Control Conf. (ACC'07), pp. 3509-3515, 2007.

[10] L. Desborough, and T. Harris, "Performance assessment measures for univariate feedforward/feedback control," Canadian J. Chemical Engineering, vol. 71, no. 4, pp. 605616, 1993.

[11] A. Cervin, J. Eker, B. Bernhardsson, and K. E. Årzén, "Feedback-feedforward scheduling of control tasks." Real Time Syst., vol. 23, no. 1, pp. 25-53, 2002.

[12] J. Zhang, L. Li, and D. Dorrell, "DQ Coupling Suppressed PID Controller for the Transmission Line Power Flow Control Using a Matrix Converter," IEEE Ind. Electron. Soc. Annu. Meeting (IECON16), Florence, Italy, pp. 6249 6254, October 2016.

[13] J. Zhang, D. Dorrell, and L. Li, "Applications of the Direct Space Vector Modulation Controlled Matrix Converter as the Unified Power Flow Controller," 8th Int. conf. power electron. motor drives (PEMD206), Glasgow, UK, pp. 1-6, April 2016.

[14] K. Ogata, "PID controllers and modified PID controllers," in Modern Control Engineering, fifth edition, PEARSON, pp. $577-651,2010$. 